\title{
TRADUZINDO O SOTAQUE DE TAWADA
}

\author{
Marina de Oliveira Santos ${ }^{1}$ \\ Gerson Roberto Neumann ${ }^{1}$ \\ 1'Universidade Federal do Rio Grande do Sul, Porto Alegre, Rio Grande do Sul, \\ Brasil
}

\begin{abstract}
Resumo: Este artigo tem como objetivo analisar o ensaio Akzent, escrito em língua alemã pela escritora japonesa Yoko Tawada. Também se propõe realizar uma discussão a respeito do estilo de escrita da autora e sobre como categorizá-la. Por fim, é descrito o processo de tradução de Akzent, que em português recebeu o título de Sotaque, seguindo-se a tradução do referido ensaio.

Palavras-chave: Tradução; Literatura Exofônica; Literatura em Língua Alemã; Identidade; Migração
\end{abstract}

\section{TRANSLATING TAWADA'S ACCENT}

\begin{abstract}
This article aims to analyze the essay called Akzent, written in German by the Japanese writer Yoko Tawada. It also proposes to conduct a discussion about the author's writing style and how to categorize it. Finally, the Akzent translation process is described, which in portuguese received the title of Sotaque. Additionally, the translation of the essay is presented.
\end{abstract}

Keywords: Translation; Exophonic Literature; German Language Literature; Identity; Migration 


\section{Identidade e alteridade: dois conceitos-chave para compreender Akzent}

Stuart Hall (2006), em Identidade cultural na pós-modernidade, descreve os avanços na teoria social que ocorreram no período da modernidade tardia e que tiveram como maior efeito o descentramento final do sujeito cartesiano. Entre estes fatores, que incluem o materialismo histórico de Marx e o conceito de inconsciente de Freud, Hall cita também a teoria de Ferdinand de Saussure.

Para Hall, a consciência de que fazemos uso da língua somente nos posicionando no interior dos sistemas de significado da nossa cultura (40) foi um fator fundamental para a nossa identificação como sujeitos modernos descentrados. Foi neste momento que adquirimos a percepção de que "a língua é um sistema social e não um sistema individual". E de que "não podemos, em qualquer sentido simples, ser seus autores". (40) É dessa forma, relacionando a teoria linguística de Saussure e os estudos sobre o inconsciente difundidos por Freud e, posteriormente, seguidos por Lacan, que Hall descreve um sujeito que não possui a autoria total sobre suas próprias afirmações e que, incapaz de possuir uma identidade fixa e unificada, desenvolve sua noção de Eu através de um "jogo de espelhos" entre si próprio e o Outro.

Além disso, Hall também aponta a forma como não existe uma fixidez em relação ao significado das palavras e demonstra que, no interior do código da língua, os significados surgem pela diferença:

Nós sabemos o que é 'noite' porque ela não é o 'dia'. Observa-se a analogia que existe aqui entre língua e identidade. Eu sei quem 'eu' sou em relação com 'o outro' [...] que eu não posso ser. Como diria Lacan, a identidade, como o inconsciente, 'está estruturada com a língua'. (Hall 40)

Notamos aqui que, dessa forma, Hall aponta a língua como elemento fundamental da identidade. Ambas teriam, além do mais, a 
mesma instabilidade: a língua através da impossibilidade de encerrar em um significante um único significado; e a identidade, que pela constante perturbação provocada pela diferença, seria incapaz de se fixar em um único conceito de sujeito cognoscente e racional. (41)

No entanto, não é somente para ele que a língua apresenta este papel fundamental. Franz Fanon, em Pele Negra, Máscaras Brancas, dedica a parte inicial de sua obra para tratar sobre a maneira como a linguagem se insere nas relações do sujeito com a experiência colonial. Através de sua abordagem psicanalítica, o autor aponta que no ato da fala está inserida a adoção de uma cultura e de uma civilização. (33) Fanon, que atribui à posse da linguagem "uma extraordinária potência", afirma que possuir uma linguagem significa possuir também "o mundo que essa linguagem expressa e que lhe é implícito" (34).

Não é somente na inserção em uma cultura e na formulação da identidade, porém, que Fanon percebe o papel fundamental da língua. O autor afirma categoricamente que "falar é existir absolutamente para o outro" (33). Com esta afirmação, Fanon demonstra a importância que atribui à linguagem em relação ao processo de alteridade.

Julia Kristeva também relaciona língua e alteridade de maneira fundamental na análise que faz a respeito da figura do estrangeiro em Estrangeiros para nós mesmos. A autora estabelece nesta obra a figura do estrangeiro como uma figura do Outro, que se estabelece em relação ao Eu e o descreve como ser que habita em nós, como a "face oculta da nossa identidade" (09), ao mesmo tempo em que vê na convivência com ele um convite à prática da alteridade: "Não se trata simplesmente, no sentido humanista, de nossa aptidão em aceitar o outro, mas de estar em seu lugar - o que equivale a pensar sobre si e a se fazer outro para si mesmo." (21)

No capítulo "O silêncio dos poliglotas", Kristeva aborda diretamente a relação do estrangeiro com a língua estrangeira por ele agora falada, assim como a relação dos nativos com este sujeito e com o modo como ele fala. Sobre esta relação, a autora aponta que o nativo oscila entre uma reação de condescendência e um 
sentimento de irritação: “Às vezes, uma sobrancelha levantada ou um enfático 'como?' fazem-no compreender que 'você jamais conseguirá', que 'não vale a pena', que 'pelo menos nisso não somos ingênuos'." (23) Desta forma, Kristeva compreende que o estrangeiro é encurralado em um "mutismo pluriforme", uma vez que, a impossibilitado de falar sua língua materna e sem a possibilidade de encontrar uma voz em uma nova língua, ele é impelido ao silêncio.

Não é somente no processo da fala, porém, que Kristeva reconhece uma relação de alteridade. É importante notar que a autora percebe também o rosto como um elemento de reconhecimento do Outro: "O rosto do estrangeiro queima a felicidade. Primeiramente, a sua singularidade impressiona: esses olhos, esses lábios, essas faces, essa pele diferente das outras o destacam e lembram que ali existe alguém. (11)"

Também para o filósofo francês Emmanuel Levinas o rosto é uma manifestação da alteridade. Para ele, o Outro se mostra através do rosto, que nos interpela e que se mostra a partir de sua fragilidade e desperta em nós uma responsabilidade a partir da qual se constrói a ética.

Talvez sejam estas questões que levem a primeira frase do ensaio Akzent (em português, Sotaque), terceiro texto do livro $A k$ zentfrei (sem sotaque), da escritora japonesa Yoko Tawada, a possuir uma força e um significado tão eloquentes. A autora inicia seu texto afirmando que "o sotaque é o rosto da língua falada" (22) e, com esta simples afirmação, nos leva a refletir sobre as questões de identidade e alteridade que serão discutidas ao longo do ensaio. Como o título já sugere, o elemento que guiará essa discussão é o sotaque, que no decorrer da reflexão irá se desdobrar em uma série de outros símbolos e significados.

A autora descreve as suas dificuldades, assim como as de outros estrangeiros, com a pronúncia da língua alemã, dificuldades estas que, como descreve Kristeva, poderiam impeli-la ao silêncio. No texto, Tawada propõe, porém, que estas diferenças que causam estranhamento sejam acolhidas e, mais do que isso, sejam percebidas pelas possibilidades poéticas que apresentam. 
O sotaque surge no texto relacionado com a identidade e em vários momentos em que esta relação é estabelecida, a metáfora em relação ao rosto é retomada e, então, percebemos a língua falada e, principalmente, o sotaque sendo comparado aos olhos, à boca e às linhas de expressão do rosto humano. Então, da mesma forma como os rostos humanos podem ser diversos, o sotaque surge como a manifestação da diferença.

Fica claro já em uma primeira leitura que todo o discurso do texto é voltado para o objetivo de demostrar a beleza e as possibilidades que existem na aceitação da diferença. Tawada aborda também o preconceito que existe com o sotaque, ou seja, com o estrangeiro, posicionando-se enfaticamente contra ele. De forma bastante poética, o que é criado em Akzent é uma espécie de manifesto a favor do sotaque que para ela representa identidade e um convite para a alteridade.

\section{Tawada e seu sotaque}

Estas temáticas, da língua, da identidade e do deslocamento, assim como da experiência de ser estrangeiro e de experimentar a inadequação e a estranheza de uma nova língua, são temáticas muito comuns na obra de Yoko Tawada e se relacionam intimamente com sua biografia e sua visão de mundo.

A autora, que nasceu em Tóquio em 1960, mudou-se para a Alemanha para cursar o mestrado na Universidade de Hamburgo e, depois, para Zurique para concluir seu doutorado, sempre teve a literatura como foco de seus estudos. Além de ter se deslocado durante sua formação entre estes países e de viver desde 2006 em Berlim, Tawada também esteve em diversos países da Europa, da Ásia, da América do Norte e da América Latina. Sua obra, que é bastante prolífica e conta com textos escritos tanto em língua alemã quanto em japonês, possui traduções para o inglês, francês, italiano, russo, polonês, húngaro, búlgaro, norueguês, holandês, coreano, chinês e, desde 2019, também para o português, com 
dois de seus livros publicados no mercado editorial brasileiro. Não é somente a sua obra e suas traduções que são numerosas: a autora já foi reconhecida em diversos países através de inúmeras premiações, como, por exemplo, o prêmio Akutagawa em 1992, o prêmio Adelbert von Chamisso em 1996 e o prêmio Kleist em 2016.

Quando questionada, em entrevista para a World Literature Today, sobre a maneira como percebe a questão de ser estrangeira e da procura por um "lar" fora de seu país de origem, Tawada afirma rejeitar esta visão de mundo, preferindo pensar sobre as diferenças existentes e refletir sobre como elas são percebidas e incorporadas. Para a autora, a mudança não deve ser vista como uma ameaça e as experiências de deslocamento fazem parte destas mudanças:

Nowadays, human existence is made up of continual, varied interchanges. What I refer to as ' $\mathrm{I}$ ' is made up of what I hear, what I read, what I see, and how I react to it. [...] Of course, this current 'I' has also something to do with the past, but my past, too, does not consist solely of Japan. (Tawada 43)

Esta relação que Tawada possui com estes conceitos de cultura, identidade e pertencimento se refletem na maneira como a autora enxerga a linguagem. Tawada afirma que, em uma língua estrangeira, nos encontramos "desprovidos de poder", o que faria com que muitas pessoas preferissem evitar esta experiência, por esta ser acompanhada da sensação constante de erro. Em seu ensaio intitulado "Testemunha auditiva", ela defende sua opinião a respeito da maneira como as pessoas percebem a língua:

A maioria dos alemães não afirmaria que o alemão não pode ser escrito pelos outros. Mas, indiretamente, volta e meia dão a entender que a língua tem de ser uma propriedade. Eles dizem, por exemplo, que não se pode dominar uma língua estrangeira tão bem quanto a língua materna. 
Logo se percebe que o importante para eles é o domínio. Na minha opinião, dominar uma língua é algo supérfluo. $\mathrm{Ou}$ se tem um relacionamento com ela ou não se tem nada. (Tawada 76) $^{1}$

Ainda sobre esta questão de uma suposta primazia da língua materna sobre a língua estrangeira, Tawada defende que "é uma ilusão acreditar que a língua materna é autêntica. A língua materna é uma tradução de pensamentos não ou pré-verbais" (Totten \& Tawada 95). A autora defende a linguagem como algo que não é natural para o ser humano e, então, descreve o ato de escrever em uma língua estrangeira como algo que distancia o autor dele mesmo, dando-lhe, assim, mais liberdade.

Este interesse de Tawada pela língua é elevado a tamanho preciosismo, que a autora chega a definir a palavra como a unidade inicial em seus textos: "A single word can inspire me. When this happens, I want to create a whole text out of that one word, which seems to contain the entire microcosm" (Brandt \& Tawada 43).

A autora, que transita não somente por duas línguas, mas também pelos mais diversos gêneros literários, subverte a expectativa de um certo exotismo que se imagina de uma literatura estrangeira e cria o que Lúcia Collischonn de Abreu aponta como uma "etnologia fictícia”, uma paródia do olhar orientalista, que não esconde suas origens e, no lugar disso, oferece um olhar de curiosidade para a cultura ocidental. "Diferente da etnologia, que busca entender uma cultura/etnia a partir de suas características, a etnologia fictícia de Tawada busca a não compreensão, a criação de um outsider, onde o olhar japonês ou estrangeiro é uma estratégia ficcional” (47). Dessa forma, a autora oferece um olhar de estranhamento ao leitor alemão de sua própria cultura e, até mesmo, sua própria língua.

Como definir, então, a literatura de alguém que transita entre tantos espaços, entre tantos gêneros e entre tantas línguas? No arti-

${ }^{1} \mathrm{O}$ texto Testemunha auditiva é parte do livro Überseezungen, traduzido para a língua portuguesa em 2019 por Marianna Ilgenfritz Daudt e Gerson Roberto Neumann.

Cad. Trad., Florianópolis, v. 41, no 3 p. 112-131, set-dez, 2021. 
go "'Eu sou a língua"”: a exofonia na literatura de Yoko Tawada", Gerson Roberto Neumann e Marianna Ilgenfritz Daudt traçam um histórico a respeito da maneira como a literatura escrita por estrangeiros foi classificada na Alemanha ao longo das décadas. Os autores apontam que no país se costuma seguir um "modelo de classificações literárias no qual os gêneros recebem denominações de acordo com aspectos temáticos, como Exilliteratur, Frauenliteratur, Krimi- oder Horrorliteratur [literatura de exílio, literatura feminina, literatura de suspense ou de horror]" (06). Neste contexto surgiram os termos Migrantenliteratur, literatura de migração, e Gastarbeiterliteratur, literatura de trabalhadores estrangeiros, para denominar a literatura que era produzida pelos migrantes que chegavam ao país e que tematizava as experiências de trabalho e de marginalização vivenciadas por eles.

Como aponta Werner Heidermann, que no artigo “'Literatura Chamisso"”, a literatura alemã proposta por não-alemães" também discute as distintas classificações da literatura escrita por estrangeiros na Alemanha, a reflexão sobre o Eu e o Outro tem raízes profundas no ideário alemão, indo desde o conceito de "Weltliteratur" de Goethe e chegando à definição de "literatura Chamisso". Esta denominação surgiu a partir do Prêmio Chamisso (recebido por Tawada em 1996) que é financiado pela Fundação Robert Bosch e busca reconhecer a obra de autores que escrevem em língua alemã e não têm o alemão como língua materna. Como destaca Heidermann, os primeiros autores a receber o prêmio possuíam majoritariamente um histórico de migração para trabalho, os Gastarbeiter. Então, com o colapso dos sistemas comunistas, uma onda de autores de países da Europa oriental passou a receber o prêmio. Fica claro, então, como aponta o autor, que a história do prêmio revela bastante sobre o histórico geopolítico alemão e todo seu contexto migratório. (610)

A concessão desta premiação e o próprio termo "literatura Chamisso" têm sido problematizados, porém, por críticos que percebem o critério de não ter o alemão como primeira língua como um aspecto meramente formal, que considera apenas a capacidade do autor de escrever em língua alemã, no lugar de reconhecê-lo por 
sua qualidade literária. Desta forma, a definição passou a ser percebida como insuficiente e até mesmo problemática para abarcar a literatura produzida atualmente por estrangeiros na Alemanha.

Já a respeito das outras categorizações anteriormente citadas, Gerson Roberto Neumann e Marianna Ilgenfritz Daudt apontam para o fato de que os estrangeiros que escrevem em língua alemã atualmente possuem as mais diversas origens e experiências de migração, além de apresentarem temáticas bastante distintas. Desta forma, como indica Chantal Wright no artigo "Writing in the 'Grey Zone': Exophonic Literature in Contemporary Germany", a maioria das categorias anteriores, justamente por dizerem respeito à temática das obras, apresentam um caráter que pode ser classificado muito mais como prescritivo do que como descritivo, limitando os autores a tratarem de um único assunto. Assim, em seu artigo, Wright considera como termo mais adequado para descrever este fenômeno literário, que inclui diversos autores como Tawada, o termo "exofonia".

Gerson Roberto Neumann e Marianna Ilgenfritz Daudt descrevem a literatura exofônica como uma literatura na qual "um escritor adota uma linguagem literária diferente da sua língua materna, complementando-a ou a substituindo totalmente como veículo de expressão literária." (53) Collischonn, em sua dissertação, reconhece que o termo é bastante recente no contexto acadêmico (54), mas defende que ele "evita limitações temáticas e enfatiza as experimentações estilísticas que podem ser observadas nos autores que se incluem nessa categoria" (55).

Tawada, que também é bastante ativa no debate teórico literário, costuma se definir como uma escritora tipicamente exofônica e chegou a publicar em 2003 um livro intitulado Exofonia em que manifesta sua visão sobre o termo, afirmando que "deslocar-se para fora da língua nativa não é, para a literatura, uma situação especial, é simplesmente o extremo da situação normal"2 (77).

${ }^{2}$ Tradução do texto do japonês para o português realizada pelo Prof. Dr. Andrei dos Santos Cunha, professor do Setor de Japonês, da Universidade Federal do 
Quando o assunto em questão é a tradução, Tawada também se manifesta, rejeitando a ideia de um texto original e de sua suposta superioridade sobre suas traduções da mesma forma como rejeita a ideia de superioridade da língua materna sobre uma língua estrangeira. Collischonn aponta que a autora "apresenta, em seus textos, encontros interculturais como problemas tradutórios com infinitas soluções potenciais" (42) e define o próprio processo de escrita de Tawada como uma autotradução.

\section{Traduzindo uma tradução}

Tendo em vista todas estas peculiaridades que envolvem a literatura exofônica e, principalmente a literatura exofônica de Tawada, que enfatiza a relação entre o japonês e o alemão, criando um espaço entre estas duas línguas, fica para o tradutor o questionamento a respeito de como "se meter" no meio desta relação e extrair dela um texto que alcance também o falante de uma terceira língua.

Neste contexto, podemos trazer a reflexão que Stuart Hall estabelece a respeito do conceito de tradução cultural, colocando a tradução como uma espécie de negociação entre culturas, uma cultura híbrida, que renuncia a qualquer tipo de "pureza cultural", a uma única tradição (88). Esta concepção se relaciona perfeitamente com a exofonia de Tawada e seu processo de escrita que, como define Collischonn, se trata também de um processo de autotradução que "apresenta, em seus textos, encontros interculturais como problemas tradutórios com infinitas soluções potenciais" (42). Tawada, que faz traduções e escreve também sobre traduções, rejeita a ideia de um texto original e de sua suposta superioridade sobre suas traduções da mesma forma como rejeita a ideia de superioridade da língua materna sobre uma língua estrangeira. Desta forma, a autora cede um grande espaço de autoria ao tradutor, que precisa também participar desta negociação entre línguas e se colocar nesta posição entre espaços.

Rio Grande do Sul.

Cad. Trad., Florianópolis, v. 41, no 3 p. 112-131, set-dez, 2021. 
Chantal Wright, tradutora de Tawada para a língua inglesa e teórica com diversos trabalhos a respeito da tradução de autores exofônicos, estabeleceu, principalmente em Exophony and literary translation: What it means for the translator when a writer adopts a new language, algumas propostas sobre a maneira como os textos exofônicos podem ser traduzidos. Sua teoria, que Collischonn aponta ter servido de referência para a sua tradução de Memórias de um urso polar, também guiou nossa tradução de Sotaque, oferecendo valiosos insights a respeito de como abordar a tradução de um texto tão desafiador.

Wright, que afirma ter sido influenciada pela "analytique négative" de Berman e também pelos relatos de Ashcroft, Griffiths e Tiffin sobre as estratégias de apropriação encontradas em textos pós-coloniais, para criar suas premissas a respeito da tradução de textos exofônicos escritos em língua alemã, afirma que seus apontamentos são meramente descritivos, buscando oferecer reflexões que possam ser úteis para o trabalho de outros tradutores.

A autora defende que é importante conhecer o histórico do autor que está sendo traduzido, mas que, porém, é igualmente importante conhecer o contexto cultural para o qual o texto foi escrito. Nesta perspectiva, Wright comenta o histórico de migração da Alemanha e a maneira como as primeiras gerações de migrantes que foram ao país em busca de trabalho foram marginalizadas e afirma que:

However, the bond between ethnicity and national identity which was pervasive in Germany until the early 1990s, up until the gradual repeal of the 1913 Reichs- und Staatsangehörigkeitsgesetz [Reich and State Citizenship Law] which had accorded German citizenship almost exclusively by jus sanguinis, also implies a claim to majority ownership of language which has had to be and is still being undone by exophonic writers and native speakers of German 'mit Migrationshintergrund' [with a migrational background]. (30) 
Esta questão é extremamente relevante para a compreensão de Sotaque, uma vez que, mesmo Tawada não pertencendo a um grupo de migrantes historicamente marginalizado na Alemanha, a temática de seu texto fala diretamente contra este tipo de marginalização.

Em Formação da literatura brasileira, Antonio Candido introduz uma noção de abordagem da literatura como um sistema, que integra autores, obras e público de maneira articulada. Tendo esta questão em vista, ao pensarmos na tradução de Tawada, também se faz útil a reflexão a respeito da maneira como estes três elementos se relacionam no sistema no qual a autora está inserida.

Itamar Even-Zohar, no texto Teoria dos Polissistemas, percebe a existência de uma instituição literária que se relaciona com outros sistemas culturais. Neste contexto, surge em sua teoria o conceito de polissistema literário, assim como a ideia de uma dinâmica que estabelece uma relação entre núcleos centrais e periferias neste polissitema. Em $A$ posição da literatura traduzida dentro do polissistema literário, Zohar aponta para a maneira como a literatura traduzida pode participar ativamente da modelagem de um polissistema literário, ocupando desta maneira uma posição central. O teórico aponta que "Em tal situação, a literatura traduzida é, em geral, uma parte integral das forças inovadoras e está, portanto, propensa a ser identificada com eventos importantes na história literária no momento em que eles estão acontecendo." (04)

Embora a literatura de Tawada não possa ser classificada dentro do contexto literário alemão como uma literatura estrangeira traduzida, esta dinâmica também pode ser observada em sua obra. É o que aponta Chantal Wright em "Bringt Poesie in unsere Städte!” Obrigkeitsdeutsch and Exophonic Literature. No artigo, a autora comenta sobre a maneira como Tawada e outros autores estrangeiros que escrevem em língua alemã têm suas obras diminuídas por parte da crítica que frequentemente aponta "erros gramaticais" em seus textos, de uma forma que dificilmente seria feita com autores alemães. A autora aponta também para a maneira como mesmo as críticas elogiosas muitas vezes atribuem a inventividade destes autores unicamente ao fato de estes serem estrangeiros e, portanto, 
terem supostamente uma relação pouco convencional com a língua alemã. Por outro lado, como descreve Heidermann, a literatura contemporânea de autores alemães apresenta a tendência a um padrão bastante definido, com uma narrativa compacta, monotemática e "muitas vezes bastante pontual no seu enredo baseado em um momento da história alemã" (605). Já as literaturas escritas por não-alemães demonstram uma intensa inovação temática e estilística, que leva parte da crítica e do público a percebê-los com interesse, apesar da percepção limitada e até mesmo preconceituosa que muitos outros apresentam a respeito de suas obras. Desta maneira, é possível perceber a relação destes autores com o polissistema literário alemão como uma dinâmica, na qual estes ocupam um papel central e, ao mesmo tempo, são frequentemente impelidos para as margens.

A percepção desta dinâmica é necessária para que o tradutor não corra o risco de realizar uma tradução "ingênua” ou até mesmo preconceituosa de autores como Tawada. Entre as outras premissas que Wright cita como importantes para a tradução de autores exofônicos em Exophony and literary translation: What it means for the translator when a writer adopts a new language estão também a ideia de não atribuir seus processos criativos somente ao fato de estes serem estrangeiros e estarem fazendo uma tradução literal para a língua alemã (algo bastante comum na crítica da autora turca Emine Sevgi Özdamar), assim como a ideia de não considerar qualquer fuga da norma gramatical alemã como um erro do autor devido ao seu suposto pouco conhecimento de alemão.

Consideramos as duas premissas seguintes que Wright comenta em seu artigo como os principais responsáveis por diversas reflexões e, também, algumas soluções que encontramos em nossa tradução. O primeiro diz respeito à necessidade do tradutor de estar ciente de como, para o autor exofônico, a língua por ele adotada não possui somente uma função comunicativa.

Wright cita Tawada como um exemplo bastante significativo desta questão, uma vez que ela investiga "the physiology of language(s), moving language beyond its communicative function into 
a realm where linguistic signs dictate what is signified, rather than signifieds dictating the choice of linguistic signs" (33-34). Esta consideração a respeito da escrita de Tawada foi um dos fatores que norteou nossa decisão a respeito de quais palavras seria necessário manter em alemão, levando em consideração seus valores insubstituíveis como signos para o texto.

Outro fator que serviu de referência em nossas escolhas diz respeito a outra premissa apresentada por Wright: A autora aponta que o tradutor não deve buscar ocultar o que ela definiu como "metonymic gap". Para explicar o termo, ela retorna aos escritores pós-coloniais, que, na busca por ressignificar a língua dos colonizadores para suas próprias identidades, utilizavam diversos recursos linguísticos que provocavam um abismo de compreensão entre o texto e muitos de seus leitores.

Wright considera que a mesma premissa é válida também para autores exofônicos e que, portanto, o tradutor não deve buscar explicar para seu público alvo algo que é propositalmente incompreensível para o leitor ao qual o texto originalmente se dirige. Foi nosso exercício, portanto, analisar o texto sempre com o intuito de observar se havia expressões que não seriam compreendidas ou que causariam algum tipo de estranhamento para o leitor alemão.

Sendo assim, como já comentamos anteriormente, observamos em Akzent um enfático manifesto a favor da diversidade, no qual Tawada usa diversos recursos imagéticos, fluxos de orações e frases curtas e de bastante impacto para defender seu pensamento. FeZ-se necessária para a seguinte tradução, então, uma percepção da maneira como a autora conduzia o ritmo do texto, com o objetivo de estruturá-lo em língua portuguesa com a mesma expressividade para que, então, fosse possível não apenas traduzir seu conteúdo, mas também defendê-lo com o mesmo arrebatamento com o qual Tawada o faz em língua alemã. Assim, pretendemos apresentar a seguir o resultado que obtivemos deste processo de tradução. 


\section{A tradução do ensaio Sotaque, de Yoko Tawada}

\section{Sotaque}

O sotaque é o rosto da língua falada. Seus olhos brilham como o lago Baikal, ou como o mar Negro, ou como alguma outra água, de acordo com quem está falando. Os olhos da minha fala contêm águas do Pacífico, onde inúmeras vogais nadam como ilhas. Sem elas eu me afogaria.

A língua alemã não me oferece vogais suficientes. "Lufthansa" eu pronuncio "Lufutohansa", e com isso quase toda consoante é completada com uma vogal. Onde mais eu posso ir com os meus sentimentos, que têm moradia apenas nas vogais? O que seria do mundo se só existissem consoantes? Pronuncie simplesmente " $k$ " ou "g" e perceba que efeito surge no seu corpo. Elas soam para mim como uma rejeição, uma demarcação ou um vago pretexto.

Eu me sinto desconfortável e tento, portanto, pronunciar estes sons com pouca força e levo em consideração que isso aumenta meu sotaque japonês. As consoantes de expulsão "p" e "b" também me dão dor de cabeça. Elas soam com raiva, desprezo e frieza. Eu prefiro puxar o ar para dentro na pronúncia dessas consoantes, para que elas não explodam de modo muito violento.

Existem também consoantes mais suaves. Isso não quer dizer que eu possa pronunciá-las sem sotaque. Eu confundo, por exemplo, as consoantes " $r$ " e "l". Elas são gêmeas idênticas para mim. Aqui alguns exercícios para melhorar a sua confusão: "A aranha arranha a rã. A rã arranha a aranha. Nem a aranha arranha a rã. Nem a rã arranha a aranha." - "Três tigres tristes para três pratos de trigo. Três pratos de trigo para três tigres tristes." - "Kein Bücherregal ist illegal, egal welche Bücher da stehen, genauso wie kein Mensch illegal ist, selbst wenn er mit einem Akzent spricht. ${ }^{3}$ "

\footnotetext{
${ }^{3}$ Nenhuma estante de livros é ilegal, não importa quais livros estejam lá, assim como nenhuma pessoa é ilegal, mesmo que fale com sotaque.
} 
O sotaque une inesperadamente duas palavras que normalmente não soam de forma semelhante. No meu sotaque se escuta de forma parecida "Zelle" e "Seele" (cela e alma).

Não é tarefa minha diferenciar um tom regional, um sotaque estrangeiro, uma variante social, uma deficiência na fala. Em vez disso, proponho que qualquer desvio seja percebido como uma oportunidade para a poesia.

Para mim é estranho falar em uma "variante", pois não tenho certeza se há algum "padrão". Nas aulas de idiomas no Japão, aprendi que o mais puro alemão padrão se encontra em Hannover, mais precisamente em um palco de teatro, e não em qualquer lugar da rua. Mas não existe ninguém que tenha nascido em um teatro de Hannover e nunca tenha botado os pés para fora do edifício. Então não existe gente sem sotaque, assim como não existe gente sem rugas no rosto. O sotaque é o rosto da língua falada e as suas rugas ao redor dos olhos e testa desenham, a cada segundo, uma nova paisagem. $\mathrm{O}$ falante experimentou, formou, musicalizou, moldou, nutriu, sustentou e quem sabe até mesmo depredou todas essas paisagens distantes, e isso se revela na sua pronúncia. Seu sotaque é sua autobiografia, que, regressivamente, será reescrita em uma nova língua.

O sotaque é um generoso convite para uma viagem por grandes longitudes geográficas e culturais. Em uma metrópole moderna se tem que estar sempre preparado para ser enviado em uma volta ao mundo no meio do intervalo de almoço. Uma garçonete abre a boca e já estou a caminho de Moscou, Paris ou Istambul. O céu da boca da garçonete é um céu noturno, pairando sobre sua língua, que personifica o continente euro-asiático. Sua respiração é o Expresso do Oriente. Eu embarco nele.

Quem fala com sotaque se sente em casa. O sotaque é sua casa própria, no verdadeiro sentido da palavra, pois ele é sua propriedade, que não pode ser perdida em tempos de crise econômica. Ele o carrega consigo sempre na boca e, consequentemente, pode sempre, confortavelmente, falar sua língua estrangeira na sua própria casa.

Se não existisse mais o sotaque, existiria o perigo de que se esquecesse facilmente o quão diferentes as pessoas são. 
O sotaque dá às pessoas coragem, pois ele é uma prova viva de que um adulto ainda pode aprender toda uma língua exótica. Se ele já tivesse aprendido quando era criança, ele não teria sotaque. Depois que somos mais velhos também podemos expandir nossos palatos, deixar crescer novos dentes fictícios, treinar os músculos da boca, produzir mais saliva e amaciar e arejar nossos neurônios. O destino do estudante de língua não é se ajustar a um lugar de destino. Pode-se sempre aprender uma nova língua e preservar as línguas antigas como um sotaque.

É difícil que alguém vindo de longe que não tenha sotaque não pareça estranho. Por exemplo, a filha de um alemão conhecido meu, que nasceu e cresceu nos EUA teve medo de ir aos correios na Alemanha. Porque ela não tem sotaque quando fala alemão, mas na agência ela só entende se o funcionário dos correios falar "carta registrada", "com reembolso" ou "a cobrar". Se ela tivesse sotaque, seriam compreensivos ao explicar a ela as palavras. Mas, infelizmente, ela não tem sotaque. Ela me disse que deviam pensar que ela é "uma cabeça de vento".

Pode ser uma vantagem para os poetas e as poetisas multilíngues, se as paredes dos seus cérebros forem ventiladas. Através das paredes não vedadas penetra o som de uma língua para outra e se cria uma música atonal.

Essa noite vamos comer fondue ou cuscuz? O luxuoso problema da vida cosmopolita, que se pode chamar de "o drama de ter escolhas", pode ser resolvido rapidamente com o uso de sotaque. Quem fala com sotaque, pode colocar mais de um idioma no mesmo lugar da língua. O suíço-alemão com sotaque árabe, por exemplo, pode ser um banquete para os ouvidos. Já não é necessário se decidir entre fondue e cuscuz.

Há pessoas que inconscientemente desvalorizam um falante com sotaque. Assim que ouvem uma entonação estranha, os hormônios que sinalizam situações de perigo já atingem seus neurônios. Não sei se esses genes provêm da Idade da Pedra ou se são manipulados pela mídia de massa moderna. Apesar disso, a história está cheia de experiências positivas com sotaques estrangeiros. Sem pessoas 
com sotaque holandês, por exemplo, a capital alemã ainda seria um pântano hoje.

É possível que soe ensolarado, musical, libertador e emocionante, se alguém falar "süsssländisch", mas se, por esse motivo, ele não conseguir nenhum emprego, sua voz não será mais ouvida, muito em breve. Não é pouco favorável se a fala de um jovem soar como a Yakusa ou a Al Qaeda quando ele estiver sendo interrogado pela polícia?

Hoje em dia fala-se de "origem imigrante", como se fosse algo insondável, e fundamentalmente escondido atrás das costas. O sotaque é o rosto da migração.

As línguas nativas também falam com vários sotaques. Alguns tentam reprimi-los. Caso contrário se ouve as condições de vida penosas em que elas se desenvolveram. E qual condição já não é penosa? O pai de um rapaz de Munique está enriquecendo cada vez mais através de impiedosas atividades bancárias e isso é extremamente penoso para o filho, estudante de literatura. A mãe de uma moça de Düsseldorf veio da província e, portanto, não nasceu em Düsseldorf e sim em uma verdadeira Dorf (aldeia) e a filha acha isso penoso. Injustamente. Mas não se pode extrair esse sentimento de vergonha com um sermão.

Felizmente nunca conseguiremos falar sem sotaque. Caso contrário nossa língua soaria desbotada, conformada, desinteressante, inibida, inflexível, medrosa, monótona ou fria. Ela seria assim somente um resquício deteriorado do que a língua falada poderia ser.

\section{Referências}

Ashcroft, Bill; Griffiths, Gareth; Tiffin, Helen. The Empire Writes Back. London: Routledge, 2002. 
Berman, Antoine. “La traduction comme épreuve de l'étranger”. Texte 4, (1985): 67-81.

Brandt, Bettina; Tawada, Yoko. "The Postcommunist Eye: An Interview with Yoko Tawada." World Literature Today, 01 (2006): 43-45.

Candido, Antonio. Formação da Literatura Brasileira. Belo Horizonte-Rio de Janeiro: Editora Itatiaia, 1993.

Collischonn de Abreu, Lúcia. Sonatas em neve: traduzindo a escrita exofônica de Yôko Tawada. Dissertação de Mestrado. Universidade Federal do Rio Grande do Sul, Instituto de Letras. Porto Alegre. 2017. Disponível em: https://lume.ufrgs. $\mathrm{br} /$ handle $/ 10183 / 170369$ ? show $=$ full.

Neumann, Gerson Roberto; Daudt, Marianna Ilgenfritz. “'Eu sou uma língua': A exofonia na literatura de Yoko Tawada." Cadernos do IL 58 (2019): 46-59.

Even-Zohar, Itamar. "A posição da literatura traduzida dentro do polissistema literário”. Tradução de Leandro de Ávila Braga. Revista Translatio, 3 (2012): 3-10.

Even-Zohar, Itamar. "Teoria dos polissistemas". Tradução de Luís Fernando Marozo, Carlos Rizzon e Yanna Karlla Cunha. Revista Translation, 5 (2013): $2-21$.

Fanon, Franz. Pele negra, máscaras brancas Tradução de Renato da Silveira. Salvador: Edufba, 2008.

Hall, Stuart. Identidade Cultural na pós-modernidade. Tradução de Tomaz Tadeu da Silva e Guacira Lopes Louro. Rio de Janeiro: DP\&A, 2006.

Heidermann, Werner. “'Literatura Chamisso', a literatura alemã proposta por não-alemães”. Revista Landa, 5 (2016): 604-618.

Kristeva, Julia. Estrangeiros para nós mesmos. Tradução de Maria Carlota Carvalho Gomes. Rio de Janeiro: Rocco, 1994. 
Levinas, Emmanuel. Totalidade e Infinito. Tradução de José Pinto Ribeiro. Lisboa: Edições 70, 1980.

Tawada, Yoko. Bogo no soto e deru tabi. Tóquio: Iwanami, 2003. Título em japonês: エクソフォニー——母語の外へ出る旅.

Tawada, Yoko. Akzentfrei. Tübingen: Konkursbuch Verlag, 2016.

Tawada, Yoko. "Die Ohrenzeugin". Überseezungen. Tübingen: Ed. Cláudia Gehrke, 2002, pp. 95-114.

Totten, Monika; Tawada, Yoko. "Writing in Two Languages: A Conversation with Yoko Tawada." Harvard Review, 17 (1999): 93-100.

Wright, Chantal. "Writing in the 'Grey Zone': Exophonic Literature in Contemporary Germany.” GLF-Journal, 03 (2008): 26-42.

Wright, Chantal. "Exophony and literary translation: What it means for the translator when a writer adopts a new language". Target 22.1 (2010): 22-39.

Wright, Chantal. “'Bringt Poesie in unsere Städte!' Obrigkeitsdeutsch and Exophonic Literature”. Kakanien revisited, (2008): 1-24.

Recebido em: 10/04/2021

Aceito em: 07/08/2021

Publicado em setembro de 2021

Marina de Oliveira Santos. Email: marinaoliveira.ms@gmail.com. ORCID: https://orcid.org/0000-0003-4437-4824.

Gerson Roberto Neumann. Email: gerson.neumann@gmail.com. ORCID: https://orcid.org/0000-0001-5809-6998. 